\title{
NGOS IN INDIA- UNIQUENESS AND CRITICAL SUCCESS FACTORS, RESULTS OF AN FGD
}

\author{
Sridhar M.K. and Manasa Nagabhushanam
}

In the last few decades, in India, NGOs have grown to play an important role in providing various services to the society. The increase in the number of NGOs and the range of activities of these NGOs, has called for an understanding on the uniqueness, management practices and the factors contributing to their success. The need not only comes from the organisations themselves but also from the various stakeholders of these NGOs. Research in this sector has thrown light on the diversity of NGOs and the distinctive sectoral characteristics. This paper explores the understanding of NGOs, features that bring uniqueness in these NGOs and the critical success factors. Focus group discussion and a qualitative research method have been used to bring out the factors. Based on the factors revealed by the FGD, a model of critical success factors has been developed.

Key Words: Non Governmental Organisations, Critical Success Factors, Voluntarism, Management Practices.

\section{INTRODUCTION}

$\mathrm{N}$ ON Governmental Organisations are gaining all attention in the recent years in India, mainly due to the increase in the number of NGOs and also because of the intervention of NGOs in every conceivable area of the society. Over the past decade the number of NGOs have grown to play an increasingly important part to meet the needs of the society. According to the Planning Commission of India (June 2005), there are 16430 recognised charities and a total of 1.2 million charities (PRIA, 2002). The central government funding to these organisations exceeds Rs.10 billion (VANI, 2001)

Each NGO is so unique that it is difficult to bring all of them onto one common platform. NGOs are distinguished on the bases of their size, origin, philosophy, ideological or religious affinities, economic strength, funding, beneficiaries, management practices, functional diversity, legal status, level of operation etc., (Mohanty and Singh, Voluntary Action Network India, 2001).
Each NGO has a different style of functioning, perhaps due to the fact that these NGOs are organised differently. There are NGOs organised either by government, religious entities, corporate or independent of any other body. They range from indigenous to international. These organisations exists in different forms, they are Societies, Trusts and Charitable Companies. There are countless number of voluntary organisations which are active at the grass root level, but have no legal entity, i.e., they are not formally registered under any act. Around 50 per cent of the organisations in India remain unregistered (Rajesh Tandon and Srivastava S.S., 2003).

NGOs basically work for social and community development and the interest areas being literacy, education, health, child and women welfare, environment, advocacy, animal welfare, volunteer promotion etc.

Being a major force in the society to bring about social change, each NGO claims to be successful and having met their objectives. The success claimed by these 
NGOs is a reality or a perception remains to be examined. Unlike business, where success is measured in terms of sales or profits, NGOs success is not easy to measure. NGOs do not aim at a measurable goal like profit. Their objective is more to do with social transformation among targeted beneficiaries through voluntary work. However, few of the aspects susceptible for measurement are beneficiary satisfaction which enables identification of gaps in providing services. Productivity, money spent etc., are also some measures which can be used to understand success of these NGOs.

There are efforts everywhere to streamline the NGOs and to make NGOs result oriented. The main thrust of the various confederations in India that provide a common platform for NGOs is to focus on quality appraisal of its member NGOs so as to enhance their performance potentials. There are a lot more NGO consultants who are working on injecting professionalism into the NGOs.

In this context, this research aims at understanding the unique features and the reasons for diversity among NGOs. If NGOs claim themselves as successful, what are those factors which are critical to the success of NGOs.

\section{Review of Literature}

Literature on non governmental organisations identifies the unique characteristics of such organisations and emphasises the need for extending management theories and management research to this sector. Accompanying the growth of these NGOs, there has also been a shift of emphasis in thinking, from a need to justify their existence to a concern for effective management practices within a now established sector (Butler and Wilson, 1990). Osborne says, "there is increasing need of voluntary organisations to manage and to be accountable as they take on an enlarged role in service delivery" (1996).

According to Hudson (1995) "all too often people from both the private and public sector believe or make the implicit assumption, that their management theories should be applied to third sector organisations to make them more effective. However, they are often of limited value because they fail to recognise that the critical issues are different in third sector organisations." The argument of Hudson brings out the point that these organisations are unique and the issues of these organisations are different from that of government or business.
Paton and Cornforth (1992) discussed the differences between the voluntary and other sectors and identified four main areas of divergence - distinctive purpose, resource acquisition, stakeholders and governance, and culture. Tassie et al., (1996) brings out the unique characteristics of non governmental organisations as commitment to organisational values; lack of market mechanism; vague, multiple and difficult to measure objectives; chronic resource scarcity. Beattie et al., (2002) says, "the nature of the voluntary sector and the unique characteristics of voluntary organisations not only impact the development of voluntary sector management theory but also research design, ethics and practices adopted for empirical studies." Dichter (1989) argues that NGOs often spend more time on fancy ideas about participatory development than on the nuts and bolts of basic management -- such as hiring the right staff, planning and budgeting and ensuring effective systems for the maintenance of their vehicles. Organisational problems in NGOs arise from the distinctive structural characteristics of the third sector organisations, requiring management ideas to be developed through further research on the sector rather than through 'one size fits all' solutions imported from the wider management field (David Lewis, 2003).

\section{Methodology}

To explore the range of opinions and views about the uniqueness and success factors of NGOs, Focus Group Discussion, a qualitative research method was adopted.

\section{Focus Groups}

A Focus Group Discussion is a form of qualitative research, commonly used by market research agencies, in which a group of people are asked about their attitude towards a product, service, concept, advertisement, idea, or packaging. In social sciences, focus groups allow to study people in a more natural setting than a one-to-one interview. Creation of ideas and comparison of perspectives generated by group interaction may provide a broader picture of the phenomena being studied. Focus groups are a qualitative technique allowing for 'the explicit use of group interaction to produce data and insights that would be less accessible without the interaction found in a group,' focus groups are an excellent method at establishing the why behind the what in participant perspectives (Morgan, 1990). Focus groups allow for participant focus over researcher emphasis. FGDs have the flexibility to 
explore beyond the boundaries of tightly worded questions and allow for rich, experiential data to evolve. This gives the research high face validity and the results are generally easy to understand and presented from the perspectives of the participants accessed together in a social setting (Denise Threfall, 1999). FGD is one of the traditional qualitative research techniques and was born out of pure necessity in the late 1930s. Focus groups are characteristically best suited for assessment of attitudes and cognition topics. Many researchers use focus groups as an initial appraisal technique prior to larger research programmes.

FGD though can provide greater insights into the problem in question, it suffers from certain disadvantages like too often the group finds its own agenda and the moderator will have difficult time in bringing the participants to the topic being researched. The artificial environment concocted for the focus group is another major drawback. Data are not collected in the natural setting but rather in a facility created, hence focus groups fall short and an element of residual uncertainty of data accuracy occurs.

This FGD on critical success factors of NGOs was a part of the preliminary study on NGOs so as to develop relevant research hypotheses for a research study on the management practices of NGOs. Twelve participants participated in the discussion. Of the total number of participants seven represented the NGOs. These participants either were running their own NGOs or they held key positions in the NGOs. The representation was from NGOs working in different interest areas of the society. Five participants were from the academic background, and had research experience in the NGO area. The discussion was held for four hours. The FGD was facilitated by the researcher leading the discussion. A Discussion Guide was prepared and the following discussion questions were included:

1. What are the characteristics of Indian NGOs?

2. How are non governmental organisations different? How are they unique in terms of management, practices and nature?

3. What are those factors which are critical to the success of NGOs?

There was an open atmosphere and every discussant was given an opportunity and ample time to express his/ her opinion or views. The focus group discussion was recorded and further transcribed. From the transcription, the findings were extracted.

\section{Findings of the Study}

As the discussants were both academicians and NGO representatives, diverse opinions were brought out. However, there was unanimity on most of the issues pertaining to the NGOs. The following are the factors brought out in the discussion:

\section{Uniqueness}

All participants accepted that NGOs are unique organisations and they cannot be compared either to the business or government organisations. NGOs become legal entities through registration either as a not-forprofit corporate, a society or a trust. Whereas, considering the dynamics of NGOs, the uniqueness does not come from legal status. Legally they are all the same, whether a religious organisation running an engineering college or a small NGO carrying out community based rehabilitation in a small village.

It was argued that uniqueness of NGOs comes from commitment for a cause, voluntary spirit, self motivation, strong internal vision, people skills and culture. There was a strong suggestive point from the NGO representatives that uniqueness of NGOs is astrength, and not a weakness. They also felt that if we try to make all NGOs to look similar then we would kill the individuality of NGOs.

\section{Diversity}

NGO representatives brought out that today in India, NGOs are highly diverse and there are many types of NGOs namely the BONGOs, PONGOs or GONGOs. The big NGOs like Myrada or Oxfam, the professionally organised NGOs like Pradhan or Action Aid and a lot more government organised NGOs. It was said that NGOs come in all shapes, colours and sizes. They have different ideological colours and they cannot be brought under one platform.

\section{Space}

One of the academic participants questioned the NGO representatives, if NGOs should have a space of its own and particularly acceptable to the government. In the sense that the niche has to be an area where there is dichotomy in the government or government is not in a position to work in that area. NGO representatives' emphasised that NGOs have a space but it is not necessary that it should be in dichotomy to government 
and accepted that, it is a fact that NGOs do not fill the deficit of the government. NGOs do, what government cannot do. For example, in agricultural sector, the agricultural extension officers have the zeal and enthusiasm to work in the interest of the farmers, but for some reason they do not have people skills. They can't organise people. NGOs have these skills and they are also committed to social change. NGOs steps in to save the government. That is the reason why government subcontracts, co-opts or sometimes gives in totally to NGOs. Government has also been asking NGOs to form Self Help Groups.

So what distinguishes NGOs from government are the people skills. Now, government has realised that the path to poverty alleviation and development is the SHGs. The SHGs by CNDP, Anganwadi workers or Stree Shakti's formed by government may not work as efficiently as the SHGs of NGOs. In many areas of social development, the government has opened its hands to NGOs.

\section{Working with the Government}

It was also questioned by the academic representatives on 'why NGOs hesitate to work with the local government.' It was asked if NGOs do not believe in democracy. It was also pointed out that some organisations are not ready to take funds from the government just because if they do take funds they have to work with the government. NGO representatives also accepted that sometimes the support of the government is necessary. There are also examples of government abusing NGOs in many forms. Government out-sources NGOs paying a very small amount almost one tenth of the normal rates. If NGOs are merely motivated by an external factor such as the government grant, such NGOs can not sustain in the long run and they evaporate over a period of time. But it was accepted that in some situations the support of government is necessary to implement the projects.

\section{Vision}

There was unanimity in accepting that NGOs have a vision and it is in the form of a craving to bring about social change. But it is rarely spoken and expressed. NGO representatives felt that vision does not come externally but that it is very strong within. There may be few organisations, around 25 per cent where the vision is externally imposed, but for 75 per cent of the NGOs in India, the urge is within, they have started just because they want to bring about social change. They are genuinely altruistic:

A researcher recognised that there are two types of NGOs namely, agenda driven and vision driven. The agenda driven organisations start just because there is a funding available either from the government or from International funding agencies. Whereas, in case of vision driven NGOs they start with a vision and the structure evolves naturally and agenda is a by-product of that vision.

\section{Missionary Zeal}

It was also reiterated that there is a necessity to view voluntary organisations from a historical perspective. Examples of organisations with missionary zeal were named and their success stories were narrated. It was emphasised that voluntary organisations that succeeded in India are those that have had a missionary zeal.

\section{Structure}

As the academic participants were mostly from the Management background they raised the issue of the structure of the organisation. There was a perfect match between the perception of the academic participants and the experience of the NGO participants. It was brought out that there is structural difference between a NGO and a Business Organisation. A business organisation normally has a formal structure whereas in an NGO the structure is loosely held. NGOs have a strong informal structure. The cross functional links in a business which is much talked about these days, have been adopted by NGOs long back. The NGOs do not work on functional lines but work with a vision. Most of the NGO work is at the grass-root level and hence mostly operate in the fields.

However, few NGO representatives also felt that in the present day context where the NGO's numbers are growing, there is a need to structure a system for every organisation.

\section{Value Delivery}

For a complaint by the academic participant that some NGOs are motivated merely by an external factor such as the government grant or funds from government agencies. For this the NGO representatives felt that there are such NGOs but they can not sustain in the long run. Only those NGOs who have deep roots in society and those that are true service and value delivery 
organisations can sustain the uniqueness of NGOs. NGOs that are serving at the grass-roots are able to deliver to true value to the beneficiaries and hence, value delivery was identified as one of the key factors for success.

\section{Voluntarism vs. Professionalism}

The views with respect to voluntarism and professionalism were divergent. Though there was acceptance of the fact that NGOs should have the true spirit of voluntarism, the views were different with respect to whether NGOs need to be professionalised or not. NGO representatives felt that there was a great deal of voluntarism in early voluntary organisations, and today to be successful these organisations should go back to their voluntary spirit. Few of them felt that corporate culture and professionalism in large international organisations is shaking the voluntary movement in India and is shattering the very fabric of the voluntary spirit of NGOs in India today.

It was also felt that earlier NGOs were small and had very little money, they thrived with voluntarism and it was a passion. Today, the scale of funding has increased 50 fold. Earlier, NGOs had a budget of four to five lakhs per annum. Today, NGOs have a budget of four to five crores. There were no large resources to be managed. Slowly these organisations have started growing, have branched out, and have started manufacturing and selling, bringing in design experts etc., they have also started using internet, web design etc. All these have replaced voluntarism by professionalism and also increased the dependence on donors. At the same time, few felt that professionalism is not an alien to the NGO sector and in fact every NGO is professional. It was also felt that the meaning of professionalism is not properly interpreted. Hence, NGOs need voluntarism on one hand and also need to be professional in their approach. However, others still felt that voluntarism should not be replaced by professionalism; once it is replaced an NGO may lose its ground.

\section{Culture and Values}

There was a strong voice to the fact that, the management in NGOs stems from culture. One NGO representative felt that though these organisations are not very familiar with the management terminology, each organisation has a distinct culture and uses the best method that suits the organisation culture and the situation. It was felt that
NGOs survive and succeed only because the thread of culture and values bonds all those volunteers who work for these NGOs.

\section{Leadership and Succession}

Coming to the issue of leadership as a factor for success, NGO representatives felt that in a vision driven NGO the leader is a visionary. The success of NGO depends on how well the leader articulates the vision to the rest of his group that is involved in voluntary work. The academic participants felt that only the founder leader would be a visionary and the second rung of leaders would lose their sense of the vision and objectivity, hence the culture of the organisation cannot be furthered. NGO representatives said that it is a challenge to develop a second rung of leaders. In a NGO the baton has to be passed on through the culture only. Succession is a weak link in these organisations, hence, long term survival and success of NGOs gets affected.

However, NGO representatives said that Visionary Leadership is one which makes one successful NGO different from the rest.

\section{Other Factors}

There were also few other points emphasised in the course of the discussion. The NGO representatives also said that organisations that are more specialised and those which have a focused objective are successful. Another factor that got mentioned was to understand needs of the target beneficiaries for the success of the programmes of an NGO.

The whole question of success of these NGOs being a perception or reality remained. NGO representatives felt that these organisations normally claim to be successful and never speak of failures. NGOs deal with more serious issues compared to that of corporate organisations. When it comes to objective analysis, NGOs do not see whether what they have done is right or wrong. NGOs normally do not have the time, patience or skills to assess themselves. An NGO index is very much essential to measure the organisation's success. Instead of a norm reference it is necessary to develop a criterion reference. This criterion reference should be used by NGOs for self appraisal. NGOs are perhaps being glorified; and there is a possibility that they are causing harm to the society.

Few other representatives from the NGOs felt that whatever programmes we do to the beneficiaries are 
certainly measurable. There are measures to measure the success of NGOs. But these measures are both tangible and intangible. To understand the work of these NGOs there is a need to use both the measures. It was also said that measurement of success can also be done taking the inputs, outputs and efficiency into consideration. Technology was considered as one supplement to measure success.

\section{Conceptual Model on NGOs Uniqueness and Critical Success Factors}

The above discussion of the findings reveals that NGOs are unique organisations and have a totally different approach in thinking and functioning. It also brings out the fact that there are definitely certain factors that contribute to the success of the NGOs. These factors can be classified into two categories namely the hard factors that are measurable and the soft factors that are difficult to measure.

Critical Success Factors of NGOs

\begin{tabular}{|l|l|}
\hline Soft Factors & Hard Factors \\
\hline Vision & Structure \\
\hline Missionary zeal & Size \\
\hline Distinct culture & Objectives \\
\hline Leadership & Focus \\
\hline Value delivery & Targets \\
\hline Shared values & Funding \\
\hline Succession & Professionalism \\
\hline Unique space & Government support \\
\hline
\end{tabular}

NGOs are unique organisations and their uniqueness comes from the factors like Vision, Voluntarism, Space, Culture, Leadership, Succession, Missionary Zeal, Value Delivery to the Society, Sharing of Values, Inherited Culture etc., and these unique factors of success are listed above as the soft factors. The hard factors are those factors that are essential but giving excess attention to these factors may make NGOs lose their uniqueness. Such factors include Structure, Size, Short Term Objectives and Targets, Funds, Professionalism, Government Support, Sector-wise Specialisation, Working with Partners etc. It can also be said that the hard factors are tangible and the soft factors are intangible.

However, one should realise that success of an NGO is not an instant outcome of its efforts. It has to pass through different phases, right from establishment, to stability and later it can accomplish or achieve success. Though all factors are important, the importance given to the factors vary from one phase to another. The fact is that all factors contribute in different phases of the journey to success. Taking into account the literature on uniqueness and diversity amongst NGOs and the findings of the focus group discussion, here is an effort to develop a model of critical success factors of NGOs. This model shows that there are a host of success factors and all these factors are required through all stages of an NGO. The model depicts three stages namely, Establishment Stage, Continued Existence or Survival Stage and the Success Stage. Though all the factors are needed for success, few are more important in the establishment stage, few in the survival stage and few others in the success stage.

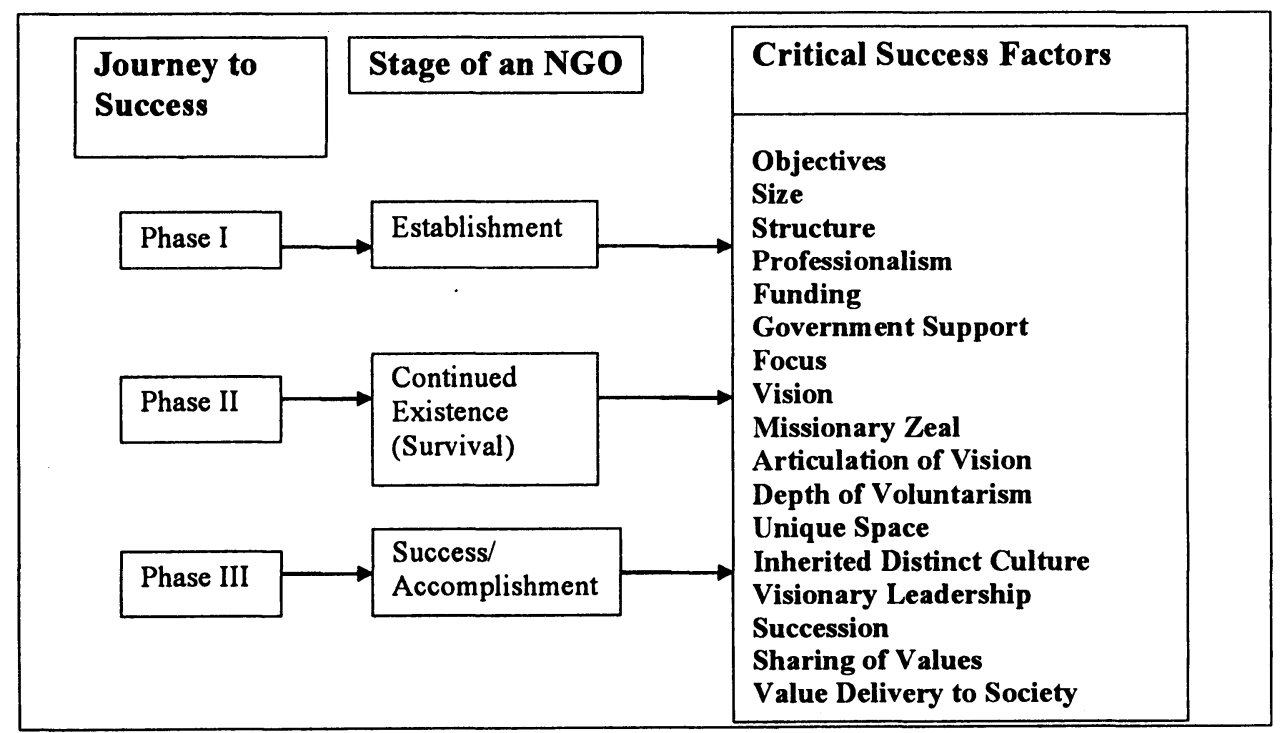

Proposed Model of Critical Success Factors

VISION-The Journal of Business Perspective • Vol. 12 • No. 2 • April-June 2008 
The above model brings out certain important dimensions of NGOs in India. There is an attempt to identify what is important for NGOs and what really determines the success of NGOs. It also explains no factor can be ignored at any point of time but the emphasis on these factors varies depending on the phase of the journey to success. However, this is only an initial model which may help NGOs and researchers to look into the success factors at various stages of the journey of NGOs towards success.

\section{Acknowledgments}

We are grateful to the participants of the Focus Group Discussion held on $25^{\text {th }}$ September 2006 with whose contribution this article is made possible.

Ms.Indumathi Rao- Director, CBR Network

Dr. Poornima Vyasulu- Director, CBPS Bangalore

Prof. Shankarnarayan-Professor, Acharya Institute of Management

Col.Murthy Rajan- Chief Operating Officer, Akshara Foundation

Dr. Venkatesh H.R.- Professor, Dayanand Sagar Institute of Management

Mr. Sripad Rao- Director, Hindu Seva Prathishtana

Mr. Srinivas- Hindu Seva Prathishtana

Mr. Venkatesh- Founder Director, Chandana Art Foundation

Mr.Srikanth- Founder Director, 18 ${ }^{\text {th }}$ Horse Foundation

Mr. Manjunath- Vice President, $18^{\text {th }}$ Horse Foundation

\section{REFERENCES}

Butler, R.J. and Wilson, D.C. (1990), Managing Voluntary and Non-profit Organisations: Strategy and Structure, Routledge, London.

David Lewis (2003), "Management of Non-Governmental Development Organisations towards a Composite Approach, Public Management Review, 5.3, pp. 325-344.

Denise Threlfall, K. (1999), "Using Focus Groups as a Consumer Research Tool," Journal of Marketing Practice: Applied Marketing Science, 5.4, pp. 102-105.

Dichter, T.W, (1989), "Development Management: Plain or Fancy? Sorting Out Some Muddles," Public Administration and Development, 9, pp. 381-93.

Hudson M. (1995), Managing Without Profits: The Art of Managing Third Sector Organisations, Penguin, London.

Manoranjan Mohanty and Anil K Singh (2001), Voluntarism and Government, Policy, Programme and Assistance, Voluntary Action Network India Publication. New Delhi.

Morgan, D.L. (1990), Focus Groups as Qualitative Research, Sage Publications, Newbury Park, CA.

Osborne, S. (1996), Managing in the Voluntary Sector (Ed.), International Thomson Business Press, London.

Paton, R. and Cornforth, C. (1992), "What is Different about Managing in Voluntary and Non Profit Organisations?" in J. Batsleer, C. Cornforth and R. Paton (Eds.) Issues in Voluntary and Non-profit Management, Milton Keynes: OU, Addison-Wesley, Workingham.

Rajesh Tandon and Srivastava S.S. (2002), Invisible, Yet Widespread: The Non-profit Sector in India, Participatory Research in Asia Publication, John Hopkins University Press, USA.

www.planningcommission.nic.in, official website of the Planning Commission, Government of India.

Stark Biddle, C. (1984), The Management Needs of Private Voluntary Organisations, USAID Publication, Washington.

M. K. Sridhar (bharathvasi@vsnl.net) is Reader at the Canara Bank School of Management Studies, Post Graduate Department of Management, Bangalore University. He has 29 years of experience in teaching Communication and Managerial Skills, Marketing Management, Marketing of Services, Compensation Management, Training and Development, Business Ethics and Business Negotiations.

Manasa Nagabhushanam (manasa sudarshan@yahoo.com) is an Assistant Professor in the Department of Management Studies at PESIT. She has an academic experience of 19 years and is the Editor of PES Business Review, a Peer Reviewed Journal of Management. 